\title{
A novel method of personnel cooling in an operating theatre environment ${ }^{\dagger}$
}

\author{
Aaron R. Casha ${ }^{a, *}$, Alexander Manchéa, Liberato Camillerib, Marilyn Gaucic, \\ Joseph N. Grima ${ }^{d}$ and Michael A. Borge,f
}

\author{
a Department of Cardiac Services, Mater Dei Hospital, Msida, Malta \\ b Department of Statistics and Operations Research, Faculty of Science, University of Malta, Msida, Malta \\ c Department of Anaesthesia, Mater Dei Hospital, Msida, Malta \\ d Metamaterials Unit, Faculty of Science, University of Malta, Msida, Malta \\ e Department of Infection Control, Mater Dei Hospital, Msida, Malta \\ f Department of Pathology, Faculty of Medicine, University of Malta, Msida, Malta \\ * Corresponding author. Department of Cardiac Services, Mater Dei Hospital, Msida MSD 2090, Malta. Tel: +356-25455486; fax: +356-25454154; \\ e-mail: aaron.casha@um.edu.mt (A.R. Casha).
}

Received 24 February 2014; received in revised form 9 May 2014; accepted 21 May 2014

\begin{abstract}
An optimized theatre environment, including personal temperature regulation, can help maintain concentration, extend work times and may improve surgical outcomes. However, devices, such as cooling vests, are bulky and may impair the surgeon's mobility. We describe the use of a low-cost, low-energy 'bladeless fan' as a personal cooling device. The safety profile of this device was investigated by testing air quality using 0.5 - and $5-\mu \mathrm{m}$ particle counts as well as airborne bacterial counts on an operating table simulating a wound in a thoracic operation in a busy theatre environment. Particle and bacterial counts were obtained with both an empty and full theatre, with and without the 'bladeless fan'. The use of the 'bladeless fan' within the operating theatre during the simulated operation led to a minor, not statistically significant, lowering of both the particle and bacterial counts. In conclusion, the 'bladeless fan' is a safe, effective, low-cost and low-energy consumption solution for personnel cooling in a theatre environment that maintains the clean room conditions of the operating theatre.
\end{abstract}

Keywords: Personnel cooling $\cdot$ Theatre safety $•$ Bladeless fan

\section{INTRODUCTION}

Cooling of theatre personnel is important to maintain concentration and extended work times [1], particularly during hot spells in warmer climates, when air-conditioning units may not cope. The theatre ambient temperature required to provide comfort for the surgical team can increase the risk of patient hypothermia and its known consequences $[2,3]$. Traditionally, the use of electric fans within theatres has been discouraged because of fears of air turbulence and the proven relationship between forced air devices and surgical site infections [4, 5]. However, neither the British Association of Perioperative Practice 2007 nor the American AORN Perioperative Standards and Recommended Practices 2013 guidelines on theatre environment specifically prohibit the use of fans in theatres [6].

The 'bladeless fan' uses a high-speed turbine to compress air that exits from multiple jets over an aerofoil that entrains a further 10-fold forward flow of air from the device. The manufacturer claims that, due to the high turbine speed, dust cannot settle within the housing and that the airflow from the device is laminar. The 'bladeless fan' has several theoretical advantages when

${ }^{\dagger}$ Received a third place Poster Award at the 14th Congress of the International Federation of Infection Control, St Julians, Malta, 12-15 March 2014. utilized in an operating theatre environment, including not disturbing the laminar airflow in a theatre, and not spreading fomites in the way a conventional fan with dusty blades can. The airflow speed can be adjusted and does not present annoying air buffeting that can affect fine suturing.

We investigated the use of the 'bladeless fan' in a theatre environment in a preliminary study to assess its safety, in particular whether its use was associated with an increase in particle counts of various sizes and counts of airborne bacteria.

\section{METHODOLOGY}

We tested the 'bladeless fan' (Dyson Air Multiplier ${ }^{\circledR}$, Dyson, Ltd, Malmesbury, UK) by simulating normal operating theatre conditions and measuring whether airborne particle counts changed substantially with the device in use. Air sampling was performed using a Solair 3100 particle counter (Lighthouse Worldwide Solutions, Fremont, CA, USA) and an SAS air sampler (Bioscience International, Rockville, MD, USA) to achieve bacterial air counts using Tryptone Soya Agar.

The microbial air sampler and particle counter were placed on an operating table covered with a sterile gown to simulate the operating 
field. We first tested the device in an empty theatre, with a second run of testing undertaken $15 \mathrm{~min}$ into the simulated operation in a theatre occupied by ten members of staff, included a gowned surgeon in the normal operating position. A third run (Fig. 1) was performed $1 \mathrm{~h}$ later, with the Air Multiplier both on and off.

Two-way ANOVA with interaction was performed to assess the impact of fan use and staff count in the theatre on bacterial counts, and 0.5 - and $5-\mu \mathrm{m}$ particle counts.

\section{RESULTS}

The results (Fig. 1) showed no statistical difference in either particle counts or airborne bacteria with the use of the Dyson Air Multiplier, even with the presence of ten individuals in the



Figure 1: Results of average particle counts $(0.5$ and $5 \mu \mathrm{m})$ and bacterial counts during a simulated operation with and without the Dyson Air Multiplier. operating theatre. Two-way ANOVA testing showed that the staff count in theatre was an almost significant predictor of bacterial counts at $P=0.06$ and large particle counts $P=0.09$, but that other predictors were not significant; in particular, the fan was the least significant predictor especially with regard to bacterial count and large particle counts. The $R^{2}$ value $(0.891)$ was close to 1 , indicating that the model provided a good fit.

Clean room conditions of ISO Class $7 / 8$ were maintained throughout.

\section{DISCUSSION}

Optimizing the theatre environment is important for the surgeon because surgical outcomes depend on external factors [7] and personal cooling may help to prevent an adverse event when working in a hot environment that can contribute to stress on the surgeon [1]. One-third of coronary artery bypass grafting mortality may be preventable [8] and proper theatre optimization could improve surgical outcomes more than surgical skills alone [9].

Often what is required are different zones of personal warming or cooling within the same theatre, because the requirements of a surgeon operating under a warm theatre light wearing a fluid impermeable gown are different from that of the patient, who may be prone to hypothermia [3].

Devices such as conventional fans are associated with air turbulence, which affects the carefully designed laminar airflow within a theatre and may increase wound infection rates [5]. The requirement of a laminar air flow device directed at cooling the surgeon becomes apparent because the other options for personal surgical cooling, such as cooling vests, tether the surgeon to bulky equipment and limit the surgeon's movement.

The 'bladeless fan' uses a high-speed compressor to pressurize air that exits from a series of nozzles in an aerofoil-shaped housing, such that a large volume of air can be entrained through the housing, resulting in a continuous flow of air in a laminar flow that is localized and not dispersed in the fashion of a conventional bladed fan (Fig. 2). A jet of air can be directed towards the surgeon without excessive disruption of the surrounding laminar flow that is blowing 'clean room' quality air downwards towards the patient.

Our results show that the presence of ten staff within the theatre led to a rise in mainly $0.5-\mu \mathrm{m}$ particle counts with similar but smaller increases in 5 - $\mu \mathrm{m}$ particle counts and airborne bacterial

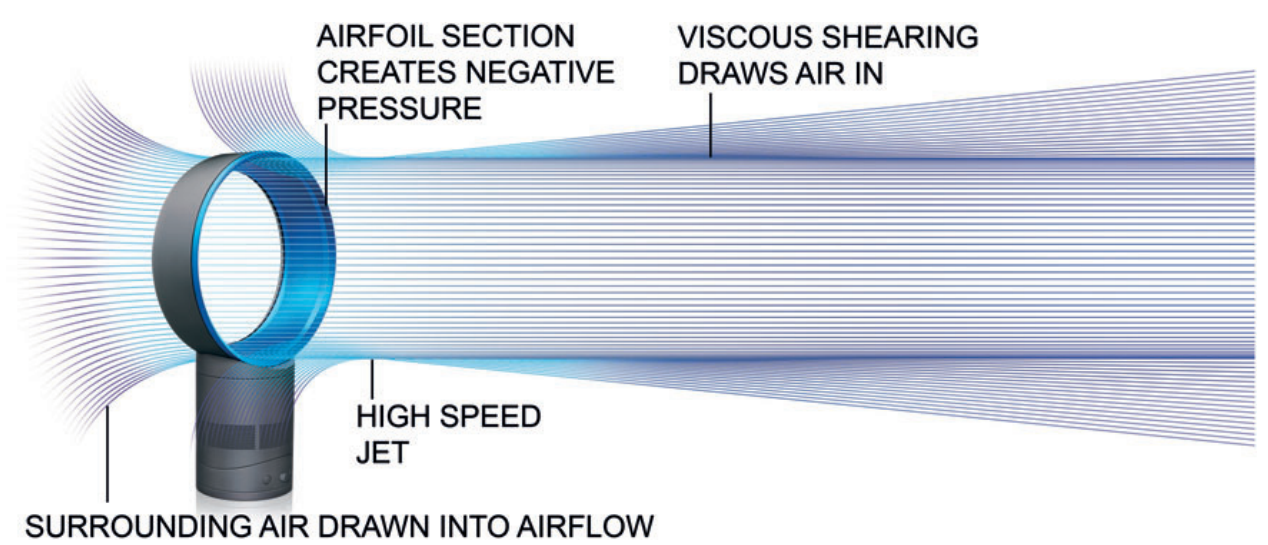

Figure 2: The 'bladeless fan' has a compressor in its base that sucks air through the vents at the base and compresses the air, which exits under pressure through slits in the round frame, travelling over an aerofoil that creates a negative pressure that sucks clean surrounding air into its airflow in a focused beam. Given that there are no rotor blades, the airflow created is laminar. Illustration courtesy of Dyson, Ltd. 
counts. However, the use of the 'bladeless fan' within the theatre during the simulated operation led to a minor, not statistically significant, lowering of both the particle and bacterial counts.

The use of the 'bladeless fan' in the operating theatre environment is a low-cost, low-energy consumption solution to the problem of personnel cooling, with low maintenance, which is safe from the patients' point of view, because it does not increase the spread of fomites within the theatre. Providing an optimized environment within the theatre may even improve surgical outcomes, because the ambient air temperature in the operating theatre can be kept higher, thus reducing the risk of hypothermia, e.g. in thoracic cases, with its consequent problems of wound infection and its effect on coagulation [10].

\section{CONCLUSION}

We conclude that the use of the 'bladeless fan' is a low-cost, safe and effective solution for personnel cooling in a theatre environment while maintaining ISO Class $7 / 8$ clean room conditions.

\section{Funding}

Funding obtained from University of Malta.

Conflict of interest: none declared.

\section{REFERENCES}

[1] Bomalaski SH, Chen YT, Constable SH. Continuous and intermittent personal microclimate cooling strategies. Aviat Space Environ Med 1995;66: 745-50.

[2] Flores-Maldonado A, Medina-Escobedo CE, Ríos-Rodríguez HMG, Fernández-Domínguez R. Mild perioperative hypothermia and the risk of wound infection. Arch Med Res 2001;32:227-31.

[3] Harper CM, McNicholas T, Gowrie-Mohan S. Maintaining perioperative normothermia. BMJ 2003;326:721-2.

[4] Belani KG, Albrecht A, McGovern PD, Reed M, Nachtsheim C. Patient warming excess heat: effects on orthopedic operating room ventilation performance. Anesth Analg 2013;117:406-11.

[5] Moretti B, Larocca AM, Napoli C, Martinelli D, Paolillo L, Cassano M et al. Active warming systems to maintain perioperative normothermia in hip replacement surgery: a therapeutic aid or a vector of infection? J Hosp Infect 2009;73:58-63.

[6] AORN. Perioperative Standards and Recommended Practices. Denver, USA: Association of Perioperative Registered Nurses (AORN) 2013.

[7] Vincent C, Moorthy K, Sarker SK, Chang A, Darzi AW. Systems approaches to surgical quality and safety. Ann Surg 2004;239:475-82

[8] Guru V, Tu JV, Etchells E, Anderson GM, Naylor CD, Novick RJ et al. Relationship between preventability of death after coronary artery bypass graft surgery and all-cause risk-adjusted mortality rates. Circulation 2008; 117:2969-76.

[9] Wong SW, Smith R, Crowe P. Optimizing the operating theatre environment. ANZJ Surg 2010;80:917-24.

[10] Luehr M, Bachet J, Mohr FW, Etz CD. Modern temperature management in aortic arch surgery: the dilemma of moderate hypothermia. Eur J Cardiothorac Surg 2014;45:27-39. 